\title{
LPS-induced CXCR7 expression promotes gastric Cancer proliferation and migration via the TLR4/MD-2 pathway
}

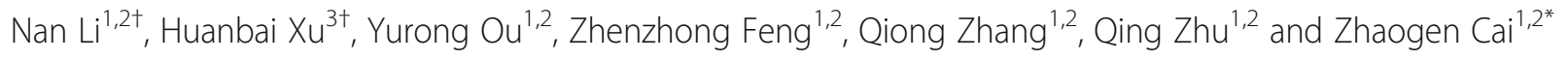

\begin{abstract}
Background: Lipopolysaccharide (LPS) from Helicobacter pylori (HP) plays an important role in gastric cancer occurrence and development. Toll-like receptor 4 (TLR4) and myeloid differential protein-2 (MD-2) are also reported to be involved in gastric cancer cell proliferation and invasion. CXC chemokine receptor 7 (CXCR7), a second receptor for CXCL12, has been detected in multiple types of tumor tissues. Nevertheless, the biological function and regulation of CXCR7 and its relationship with TLR4 and MD-2 in gastric cancer are not completely understood and therefore warrant further study.
\end{abstract}

Methods: CXCR7 expression was examined in 150 gastric cancer tissues using immunohistochemistry (IHC). RT-PCR and western blotting were used to detect CXCR7 expression in several gastric cancer cell lines (SGC7901, AGS, MGC-803, MKN-45 and BGC823). shRNAs were designed using a pGPU6/GFP/Neo vector. A CCK-8 assay was used to assess cell proliferation, and transwell assays were performed to assess cell migration. In addition, a gastric cancer xenograft model was generated.

Results: The LPS-TLR4-MD-2 pathway elevates CXCR7 expression in SGC7901 cells, and TLR4/MD-2-mediated increases in CXCR7 levels modulate the proliferation and migration of tumor cells. Knockdown of TLR4 and MD-2 demonstrated that both are essential for LPS-induced CXCR7 expression, which in turn is responsible for LPS-induced SGC7901 cell proliferation and migration. Moreover, higher TLR4, MD-2 and CXCR7 expression was detected in gastric cancer tissues than in paracancerous normal control tissues. The expression levels of TLR4, MD-2 and CXCR7 were closely related to gastric cancer TNM stage and lymph node metastasis. In an animal model, significant differences in CXCR7 expression in tumor masses were observed between the control group and experimental group.

Conclusions: The results of this study indicate that CXCR7 plays an important role in gastric cancer progression via inflammatory mechanisms, suggesting that CXCR7 could provide a basis for the development and clinical application of a targeted drug for gastric cancer.

Keywords: Gastric cancer, LPS, CXCR7, TLR4, MD-2

\section{Background}

Gastric cancer is one of the most common malignant tumors and is the third leading cause of cancer mortality worldwide [1]. Chronic inflammation is correlated with many malignant tumors [2, 3], and chronic atrophic gastritis with intestinal metaplasia is associated with an

\footnotetext{
* Correspondence: chzgenzz@163.com

${ }^{\dagger} \mathrm{Nan}$ Li and Huanbai Xu contributed equally to this work.

${ }^{1}$ Department of Pathology, The First Affiliated Hospital of Bengbu Medical College, Bengbu, China

${ }^{2}$ Department of Pathology, Bengbu Medical College, Bengbu, China Full list of author information is available at the end of the article
}

increased incidence of gastric cancer compared with the normal population [4]. Helicobacter pylori (HP) is considered a primary carcinogen in gastric cancer pathogenesis by the WHO. Consequently, chronic inflammation induced by $H P$ plays an important role in gastric cancer occurrence and development [3, 5-8]. Lipopolysaccharide (LPS) is a toxic component of the outermost layer of the $H P$ cytoderm and may contribute to long-term inflammatory injury in the gastric mucosa $[9,10]$.

Transmembrane Toll-like receptors (TLRs) are a class of signal transduction proteins referred to as pattern

(c) The Author(s). 2019 Open Access This article is distributed under the terms of the Creative Commons Attribution 4.0 International License (http://creativecommons.org/licenses/by/4.0/), which permits unrestricted use, distribution, and 
recognition receptors that can specifically recognize pathogen-related molecular patterns (PAMPs). TLR4 was first discovered as a human TLR that is sensitized by LPS from Gram-negative bacteria [11, 12]. Related research found that TLR4 is upregulated in gastric cancer tissues and has low expression in normal gastric mucosa [13, 14]. LPS can induce the formation of an LPS-TLR4-MD-2 multimer by complexing with TLR4 and myeloid differential protein- 2 (MD-2), which can further activate proinflammatory signaling pathways and facilitate the expression of corresponding cytokines and receptors $[15,16]$. Consequently, the pathogenic mechanism of TLR4 in gastric cancer progression should be studied. CXC chemokine receptor 7 (CXCR7), a second receptor for CXCL12, has been detected on the surface of multiple types of tumor tissues $[17,18]$. Nevertheless, the biological function and regulation of CXCR7 and its relationship with TLR4 and MD-2 in gastric cancer are still not completely understood and are therefore worthy of study.

In the present study, we explored the function of CXCR7 in the LPS/TLR4/MD-2 regulatory pathway in gastric cancer. LPS exposure increased the expression of CXCR7 in gastric cancer SGC7901 cells, which highly express TLR4/MD-2. Moreover, LPS stimulation induced CXCR7 expression in gastric cancer via TLR4/MD-2 signaling to promote the proliferation and migration of SGC7901 cells. Furthermore, tumor-bearing nude mice and clinicopathology were used to verify that the LPS/ TLR4/CXCR7 pathway may be critical during gastric cancer development. These results suggest that the connection between inflammation and gastric cancer may enable the development of novel methods for inhibiting tumor occurrence and development.

\section{Methods}

\section{Tissue specimens}

From 2012 to 2016, tissues from one hundred fifty gastric cancer patients (all gastric adenocarcinoma) were obtained from the Department of Pathology, The First Affiliated Hospital of Bengbu Medical College. Paracancerous normal tissues from sixty patients were used as controls. Histopathologic examination was performed by two pathologists to verify the histological diagnosis. Tumor staging was determined according to the Union for International Cancer Control (UICC) and the American Joint Committee on Cancer (AJCC) gastric cancer TNM staging system (8th edition).

\section{Cell lines and main reagents}

The gastric cancer cell lines SGC7901, AGS, MGC-803, MKN-45, BGC823 and GES-1 were purchased from the Type Culture Collection of Chinese Academy of Sciences (Shanghai, China). LPS-EB (LPS from E. coli O111:B4, cat. no. tlrl-eblps) was purchased from InvivoGen, USA. TLR4 monoclonal antibody (clone ab22048) and an MD-2 monoclonal antibody (clone ab24182) were obtained from Abcam, England. CXCR7 monoclonal antibody (clone MAB4227) and CXCL12 antibody (cat. no. 2716SD-025/CF) were obtained from R\&D systems, USA. CXCR7 antagonist (CCX771) was kindly provided by ChemoCentryx. CXCR4 antagonist (AMD3100) was obtained from Adooq Bioscience, USA. HRP-conjugated secondary antibodies for western blotting (cat. no. ab6734) were purchased from Abcam.

\section{Cell cultivation and transfection}

AGS cells were cultured in F12 medium (cat. no. 12615F, Lonza, $\mathrm{CH}$ ) supplemented with $20 \%$ fetal bovine serum (FBS), penicillin $(100 \mathrm{U} / \mathrm{ml})$, and streptomycin $(100 \mathrm{mg} / \mathrm{ml})$ at $37^{\circ} \mathrm{C}$ in $5 \% \mathrm{CO}_{2}$. The other cells were grown in RPMI-1640 medium (cat. no. 11875093, Gibco, USA) supplemented with $10 \%$ FBS, penicillin $(100 \mathrm{U} / \mathrm{ml})$, and streptomycin $(100 \mathrm{mg} / \mathrm{ml})$ at $37^{\circ} \mathrm{C}$ in $5 \% \mathrm{CO}_{2}$.

Specific siRNA sequences against TLR4 (5'-GAGC CGCUGGUGUAUCUUU-3') and MD-2 (5'-GUGGGAGA GAUUUAAAGCA-3'), as well as a scrambled control siRNA (5'-AGGACTGAGTGTACCGTCT-3' (Scram)), were designed as shRNAs and inserted into the pGPU6/ GFP/Neo vector (GenePharma, Shanghai, China) under the control of a U6 promoter. Cells resistant to G418 $(800 \mu \mathrm{g} /$ $\mathrm{mL})$ were selected and cultivated for further study $[19,20]$. The depletion of endogenous TLR4 or MD-2 by shRNA treatment was determined by RT-PCR and western blotting analyses (performed by GenePharma Biotechnology Company in Shanghai). Cell transfections were performed with Lipofectamine 2000 (cat. no. 11668-027, Invitrogen, USA) based on the manufacturer's protocol.

Reverse transcription PCR and quantitative real-time PCR The upstream primers and downstream primers for TLR4, MD-2, CXCR7 and GAPDH are shown in Table 1 [15]. Total RNA was extracted from cells or tissues with TriPure Isolation Reagent (Roche, cat. no. 11667165001) according to the standard protocol. A NanoDrop ${ }^{\circ} 8000$

Table 1 The upstream primers and downstream primers for TLR4, MD-2, CXCR7 and GAPDH

\begin{tabular}{lll}
\hline Gene & Primer & Sequence $\left(5^{\prime} \rightarrow 3^{\prime}\right)$ \\
\hline TLR4 & Forward & TGCAATGGATCAAGGACCAGAGG \\
& Reverse & TGCAGCCAGCAAGAAGCATCAG \\
MD-2 & Forward & CCGAGGATCTGATGACGATTA \\
& Reverse & GGCTCCCAGAAATAGCTTCAA \\
CXCR7 & Forward & CACAGCACAGCCAGGAAGG \\
& Reverse & GTCCCTGGCTCTGAGTAGTCGA \\
GAPDH & Forward & GGATTTGTCGTATTGGG \\
& Reverse & GGAAGATGGTGATGGGATT \\
\hline
\end{tabular}

parameter cases TLR4 ${ }^{+} P$ value MD- $2^{+} P$ value $C X C R 7^{+} P$ value 
spectrophotometer (Thermo Scientific) was used to determine the total RNA concentration. cDNA was obtained through reverse transcription of $2 \mu \mathrm{g}$ of total RNA in a $10 \mu$ reaction. PCR was performed according to the instructions. The expression products were electrophoresed on a $1 \%$ agarose gel and photographed. Quantitative real-time RT-PCR (qRT-PCR) was performed with template cDNA using SYBR Premix Ex TaqII (Tli RNaseH Plus; Takara). An ABI PRISM $7900 \mathrm{HT}$ sequence detection system was used to detect the mRNA levels of the target genes, which were normalized to the levels of GAPDH.

\section{Western blot analysis}

Gastric cancer SGC7901 cells were lysed in RIPA lysis buffer (USBiological, USA) supplemented with a protease inhibitor cocktail (cat. no. B14001, Biotool, USA). The total protein level in the nuclear lysates was measured using the Pierce $^{\text {mix }}$ BCA Protein Assay Kit (Thermo Fisher Scientific). Protein lysates $(60 \mu \mathrm{g})$ were separated on 10\% SDS-PAGE gels. The proteins were transferred to nitrocellulose using an iBlot 2 Dry Blotting System (Thermo Scientific, USA). The membranes were blocked with $5 \%$ dry skim milk in $\mathrm{PBST}$ at room temperature for $2 \mathrm{~h}$. Blots were probed with mouse monoclonal primary antibodies against MD-2, TLR4 and CXCR7 and then incubated with the appropriate HRP-conjugated secondary antibodies. The membranes were washed, and the immunoreactive bands were observed using a West Pico chemiluminescence system (Pierce). The protein expression level was analyzed compared with the GAPDH level.

\section{Cell proliferation assay}

Gastric cancer SGC7901 cells were seeded in 96-well plates $\left(2 \times 10^{3}\right.$ cells per well $)$ in $100 \mu$ l of medium containing $1 \%$ FBS with or without LPS $(500 \mathrm{ng} / \mathrm{ml})$ and cultured for 12, 24 and $48 \mathrm{~h}$. In certain experiments, SGC7901 cells were pretreated $(1 \mathrm{~h})$ with CCX771 $(1 \mu \mathrm{M})$. After $48 \mathrm{~h}$, a CCK-8 assay (Abbkine, USA) was used to assess cell proliferation. Each experiment was sampled in duplicate, and the data are presented as the mean \pm SD of three independent experiments.

\section{Cell migration assay}

A transwell assay (Chemicon) was performed to assess cell migration. Gastric cancer SGC7901 cells were resuspended in $1 \%$ FBS-medium $\left(5 \times 10^{5}\right.$ cells $\left./ \mathrm{ml}\right)$ and seeded into the upper transwell chambers containing 0.5\% BSA. Then, $1 \%$

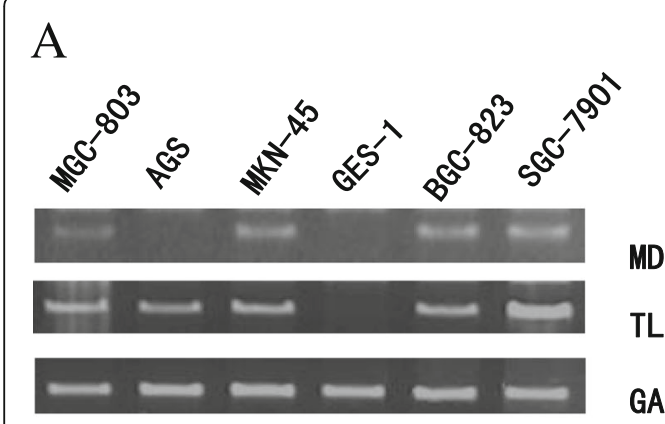

\section{C}

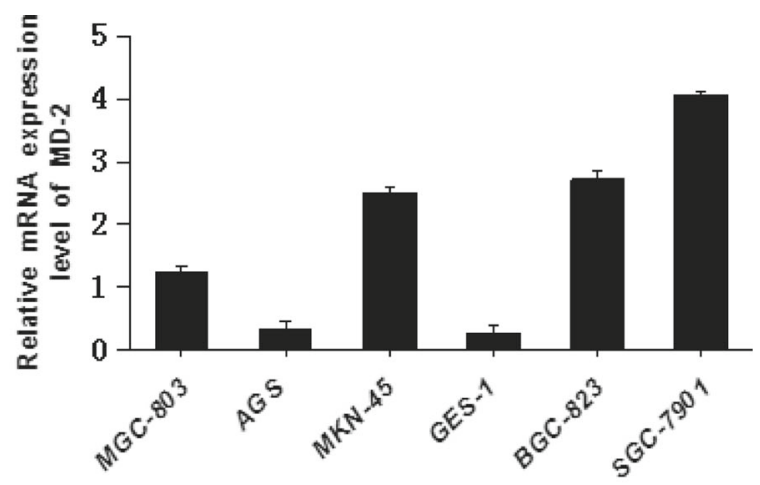

B

\section{TLR4}

GAPDH

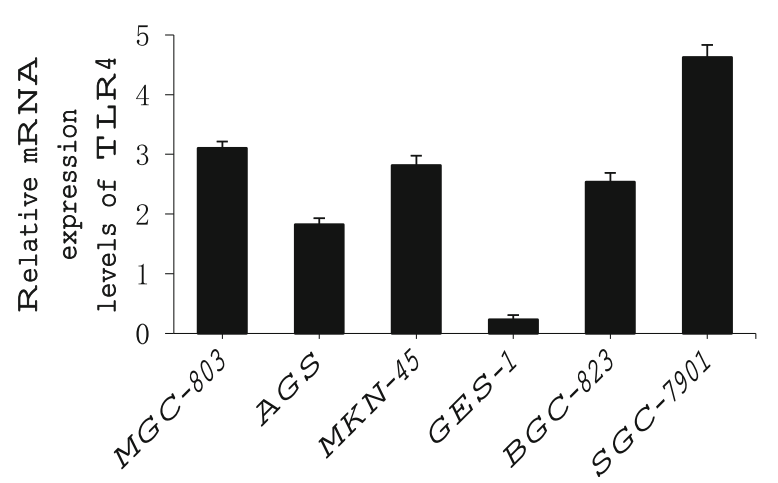

$\mathrm{D}$

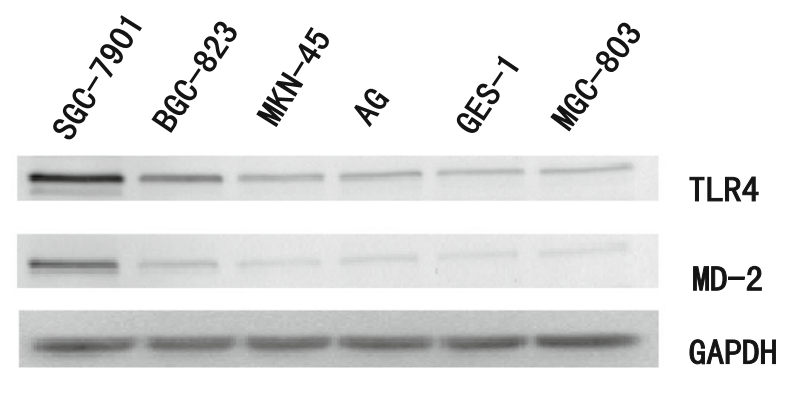

Fig. 1 TLR4 and MD-2 expression in gastric cancer cell lines. The expression of TLR4 and MD-2 was analyzed via RT-PCR (a), qRT-PCR (b, c) and western blotting (d) in gastric cancer cell lines 
FBS-medium without (control) or with CXCL12 (100 ng/ $\mathrm{ml}$ ) was added to the lower chambers. In certain experiments, SGC7901 cells were pretreated $(1 \mathrm{~h})$ with CCX771 $(1 \mu \mathrm{M})$. The experiments were performed at $37^{\circ} \mathrm{C}$ and $5 \%$ $\mathrm{CO}_{2}$ for $24 \mathrm{~h}$. After incubation, the nonmigrated cells on the upper surface of the filters were removed, and the hematoxylin-stained migrated cells on the lower surface were counted in five fields under a microscope. For quantification, each experiment was performed in triplicate.

\section{Immunohistochemistry (IHC) staining and scoring}

All archival paraffin blocks were numbered separately and cut into serial 4- $\mu \mathrm{m}$-thick sections and subjected to routine deparaffinization and rehydration. Antigen retrieval, inhibition of endogenous peroxidase activity and blocking of nonspecific binding were performed according to the kit instructions. The primary antibodies used were anti-TLR4 (mouse monoclonal antibody, Abcam, US), anti-MD-2 (rabbit polyclonal antibody, Abcam, US) and anti-CXCR7 (rabbit polyclonal, Boster Biological Technology, Wuhan, China). Rat anti-mouse IgG2bHRP (Catalog No. SBA-1186-05, SouthernBiotech, USA) was used as a second antibody. Positive tissue slices were used as positive controls, and phosphatebuffered saline (PBS) was used instead of a primary antibody as a negative control.
A

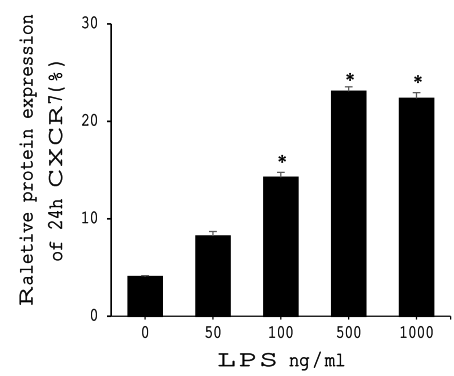

B

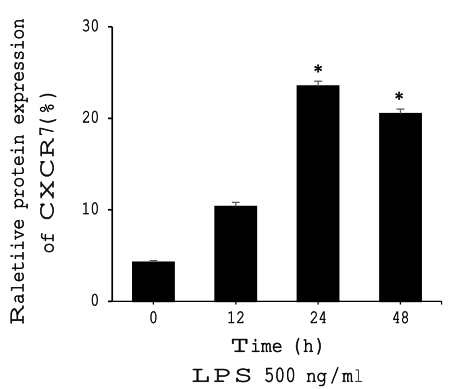

C

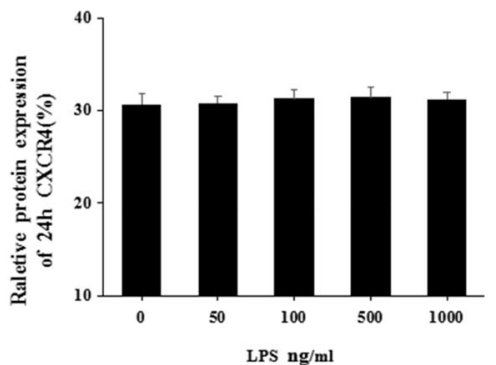

$\mathrm{D}$

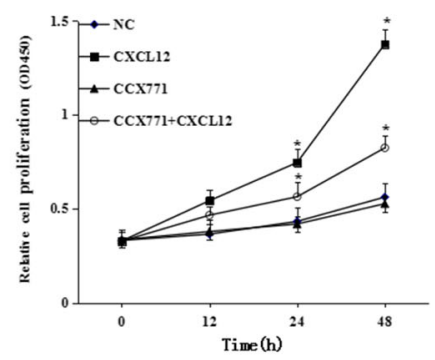

$\mathrm{E}$

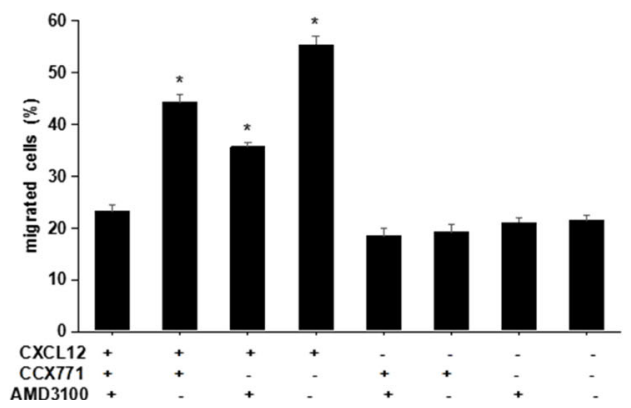

Fig. 2 LPS induced changes in CXCR7 expression in SGC7901 cells. A: CXCR7 protein expression was assessed by western blotting after SGC7901 cells were stimulated for different periods of time with $500 \mathrm{ng} / \mathrm{mL}$ LPS; B: SGC7901 cells were cultured with various concentrations of LPS for 24 h, and CXCR7 protein expression was analyzed via western blotting; C: After exposure of SGC7901 cells to LPS (500 ng/ml), CXCR4 protein expression was assessed by western blotting; D and E: After pretreatment with CCX771, SGC7901 cell proliferation and migration were largely inhibited in response to CXCL12 $(100 \mathrm{ng} / \mathrm{ml})$ after $48 \mathrm{~h}$ of incubation with LPS. ${ }^{*}, P<0.05$, vs. the NC group. The data are presented as the mean $\pm S D$ 
The IHC staining was scored according to the percentage of positive tumor cells and the intensity of the staining. The percentage of positive tumor cells was divided into four grades: 0 (no staining was observed), 1 ( $<10 \%$ of cells were positively stained), 2 (10-50\% of cells were positively stained), and 3 (>50\% of cells were positively stained). The staining intensity was scored as 0 (no staining or faint yellow), 1 (light yellow), 2 (brown), and 3 (dark brown). The final IHC score was obtained by multiplying the staining intensity score by the percentage of positive tumor cells. Scores of $0-2$ were negative, and those of 3 to 9 were positive.

\section{Animals and tumor model}

Four- to six-week-old athymic nude mice (BALB/C-nu/nu) were purchased from the Shanghai Laboratory Animal Center at the Chinese Academy of Sciences and raised in a specific-pathogen-free facility at Bengbu Medical College.
All of the animal procedures were approved by the Animal Welfare \& Ethics Committee of Bengbu Medical College. The tumors were xenografted into the left flank of nude mice through subcutaneous injection of $2 \times 10^{6}$ SGC7901 cells in $50 \mu \mathrm{l}$ of PBS. The mice were intratumorally injected with LPS $(400 \mu \mathrm{g} / \mathrm{kg})$ or the same volume of DMSO every other day. The tumor growth in the different groups was observed every 4 days, and the tumor volume was measured with calipers and calculated using the following formula: larger diameter $\times(\text { smaller diameter })^{2} / 2$. When the tumor volume reached approximately $1 \mathrm{~cm}^{3}$, the mice were euthanized. The tumor tissues were removed, and CXCR7 expression was analyzed via IHC.

\section{Statistical analysis}

The data were analyzed using the Statistical Package for Social Science software (version 19.0, SPSS Inc., Chicago, IL). The qualitative data for comparisons between groups

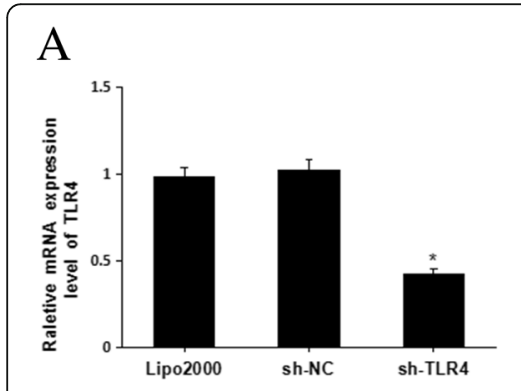

$\mathrm{B}$

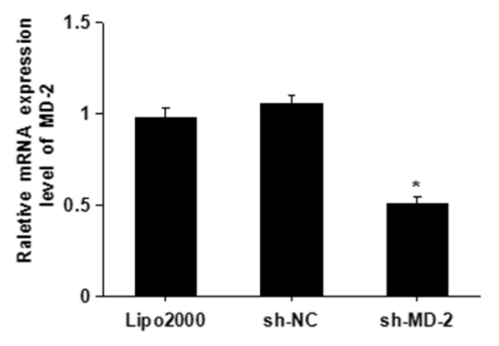

C

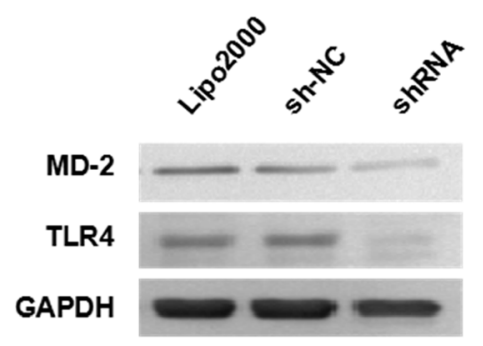

$\mathrm{D}$
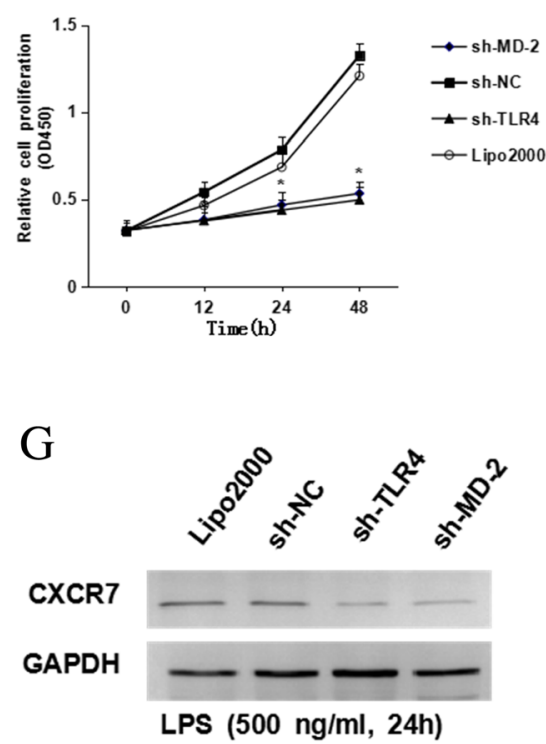

E
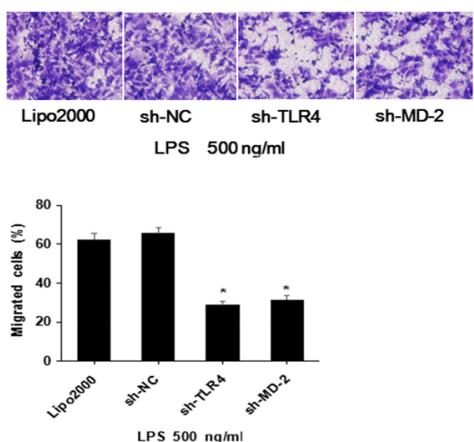

F

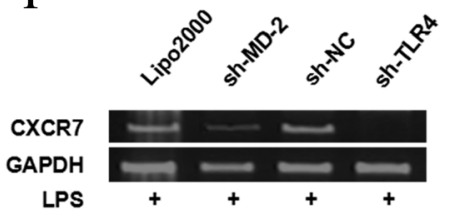

Fig. 3 The effect of TLR4 and MD-2 knockdown on LPS-induced CXCR7 expression. a-c: Gastric cancer cells were transfected with TLR4-specific or MD-2-specific shRNAs, and endogenous TLR4 and MD-2 expression levels were analyzed via qRT-PCR (a and b) and western blotting (c); $\mathbf{d}$ and e: Gastric cancer cells were transfected with TLR4-specific or MD-2-specific shRNAs and treated with 500 ng/mL LPS. A CCK-8 assay was then used to detect cell proliferation (d), and a transwell assay was used to assess cell migration (e); $\mathbf{f}$ and $\mathbf{g}$ : As described in D and E, CXCR7 expression was analyzed via RT-PCR (F) and western blotting $(\mathbf{g}) *, P<0.05$, vs. the Lipo2000 group and sh-NC group. The data are presented as the mean \pm SD 
were assessed with a chi square test and two-sided Fisher's exact test. All quantitative data are presented as the mean $\pm \mathrm{SD}$ of three independent experiments. Student's t-test was applied to assess differences between groups. A $P$ value less than 0.05 was considered statistically significant.

\section{Results}

Expression of TLR4, MD-2 and CXCR7 in gastric cancer cell lines

We investigated the mRNA and protein expression levels of TLR4 and MD-2 in human gastric cancer cell lines (SGC-7901, AGS, MGC-803, BGC-823 and MKN-45) and normal gastric epithelial GES-1 cells using RT-PCR and western blotting. The results showed that the mRNA and protein expression of both TLR4 and MD-2 was higher in gastric cancer lines than in normal gastric epithelial GES-1 cells (Fig. 1a-d). The highest expression level of both TLR4 and MD-2 was observed in the SGC-7901 cell line. Additionally, we detected CXCR7 expression in the above cell lines and found that CXCR7 expression was low in general. By comparison, the level of CXCR7 expression was slightly higher in SGC7901 cells, whereas CXCR4 expression was relatively high in these cells. Accordingly, the SGC7901 cell line was selected to study the TLR4/MD-2 signaling pathway.

\section{LPS elevates CXCR7 expression to promote SGC7901 cell proliferation and migration}

We treated SGC7901 cells with LPS and observed the effects on proliferation and migration through CXCR7. When SGC7901 cells were stimulated with different concentrations of LPS, CXCR7 expression increased in a concentration-dependent manner up to $500 \mathrm{ng} /$ $\mathrm{mL}$ (Fig. 2a). When cells were treated with $500 \mathrm{ng} / \mathrm{mL}$ of LPS for 12, 24 and $48 \mathrm{~h}$, CXCR7 expression increased in a time-dependent manner up to $24 \mathrm{~h}$ (Fig. 2b). In contrast with LPS-induced CXCR7 expression changes in SGC7901 cells, LPS-induced CXCR4 expression did not exhibit a marked increase (Fig. 2c). We next used CCX771 (a new CXCR7-specific antagonist) and CXCL12 (an endogenous CXCR7 ligand) to examine the role

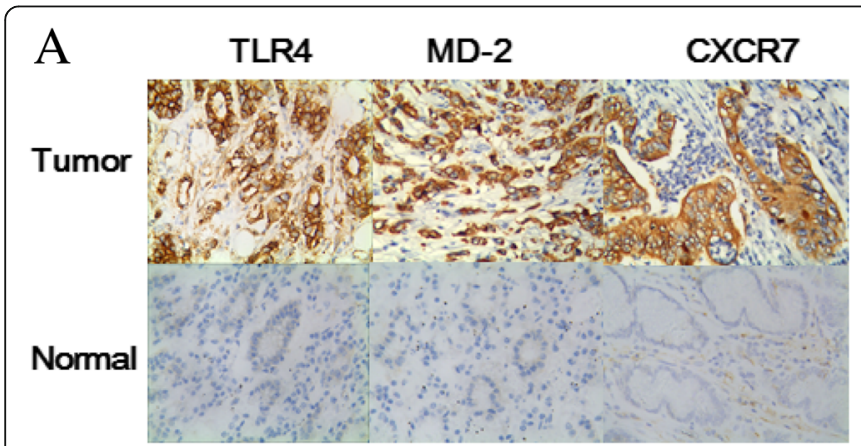

B

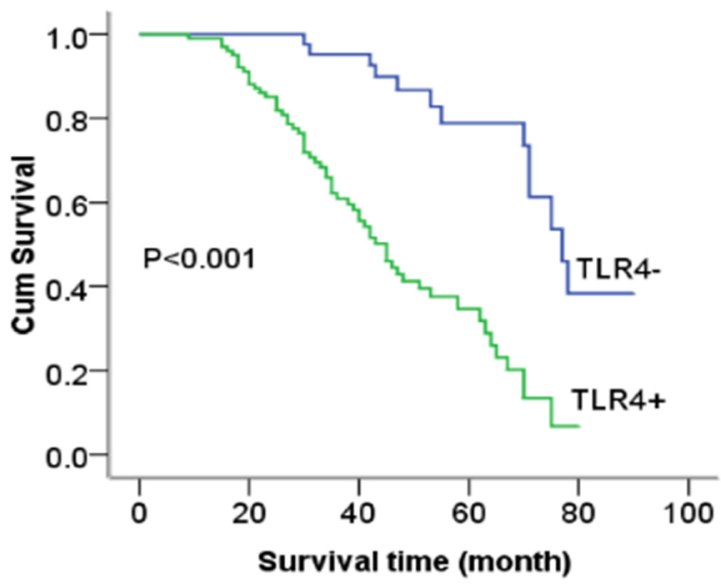

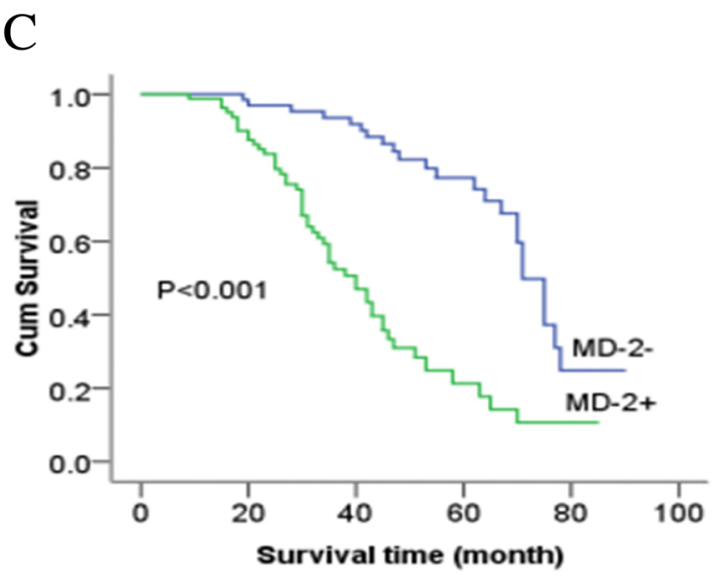

D

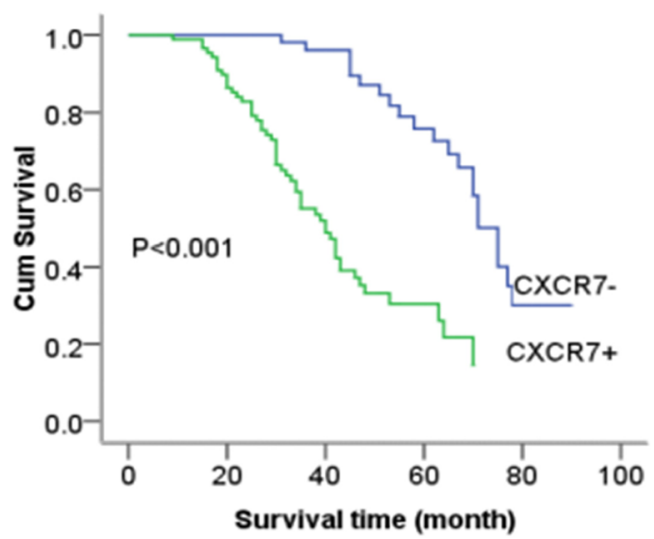

Fig. 4 TLR4, MD-2 and CXCR7 expression in gastric cancer indicates poor prognosis. a: Representative immunohistochemical staining of TLR4, MD-2 and CXCR7 in gastric cancer tissues and paracancerous tissues (original magnification 400x); survival curve for patients with gastric cancer expressing TLR4 (b), MD-2 (c) and CXCR7 (d) 
of CXCR7 in regulating SGC7901 cell proliferation and migration using CCK8 and transwell assays. Because CXCR4 is another receptor for CXCL12, SGC7901 cells were pretreated with AMD3100 (a CXCR4 antagonist) in some of the experiments. Upon CXCL12 stimulation and incubation with LPS, we found that SGC7901 cells exhibited significant proliferation and migration after $48 \mathrm{~h}$. After SGC7901 cells were pretreated with CCX771 or AMD3100, the proliferation- and migration-stimulating effects were reduced in the presence of CXCL12. However, CXCR7 promoted proliferation and migration more obviously than CXCR4 (Fig. 2d-e).

\section{LPS-induced CXCR7 expression is blocked by knockdown of TLR4 and MD-2}

We next investigated whether LPS-induced CXCR7 expression promotes SGC7901 cell proliferation and migration via the TLR4/MD-2 pathway. SGC7901 cells were transfected with specific shRNAs targeting TLR4 and MD-2. When endogenous TLR4 and MD-2 were knocked down by shRNA (Fig. 3a-c), LPS-induced SGC7901 cell proliferation and migration were decreased compared with the scrambled and negative control groups (Fig. 3d-e). Moreover, after SGC7901 cells transfected with anti-TLR4 and anti-MD-2 shRNA were coincubated with LPS, CXCR7 mRNA and protein expression levels did not increase. By comparison, CXCR7 expression was markedly decreased in SGC7901 cells transfected with anti-TLR4 and anti-MD-2 shRNAs compared with the control group (Fig. 3f-g). In general, these results suggest that the TLR4/MD-2 signaling pathway is essential for the LPS-induced increase in CXCR7 expression and its promotion of SGC7901 cell proliferation and migration.

\section{IHC results for TLR4, MD-2 and CXCR7 and their relationship with clinicopathologic factors}

We used IHC to analyze the clinicopathologic relevance of TLR4, MD-2 and CXCR7 expression in gastric cancer tissues. The expression rate of TLR4, MD-2 and CXCR7 in gastric cancer tissues was 68\% $(102 / 150), 54 \%(81 / 150)$ and $59.3 \%(89 / 150)$, respectively, and these rates were significantly different from those in normal gastric tissues (Fig. 4a). Our data revealed significant relationships between high TLR4, MD-2 and CXCR7 expression and lymph node metastasis and TNM stage (Table 2). However, the expression of these proteins was not significantly correlated with gender, age, tumor diameter or differentiation degree, although the expression of CXCR7 was slightly related to tumor diameter. We also investigated potential correlations between the protein expression of CXCR7 and that of TLR4 and MD-2, and we found the relationships to be significant (Table 3). In addition, the survival analysis demonstrated that the median overall survival time among 150 patients was 58.0 months. The overall survival of TLR4-positive patients was 45.0 months $(95 \% \mathrm{CI}$, 39.2-50.8), whereas the rate was 77.0 months (95\% CI, 69.6-84.4) for TLR4-negative patients (Fig. 4b). The overall survival for MD-2- and CXCR7-positive patients (40.0 months and 40.0 months, respectively [95\% CI, 33.9-46.1, 33.7-46.3]) was lower than that for MD-2- and CXCR7-negative patients (71.0 months and 75.0 months, respectively $[95 \% \mathrm{CI}, 66.8-75.2$, 69.8-80.2]) (Fig. 4c-d).

\section{LPS stimulation of SGC7901 cells promotes tumor growth in nude mice}

To assess the effect of the TLR4/MD-2 pathway on tumorigenicity in vivo, we established a nude mouse xenograft model. The flanks of athymic nude mice were subcutaneously injected with SGC7901 cells with or without LPS treatment. The tumor bulk and mass in the LPS treatment groups were increased compared with those in the control groups. When TLR4 or MD-2 was inhibited using shRNA in SGC7901 cells, LPS-induced tumor growth was considerably restrained in the knockdown groups compared with the scrambled shRNA

Table 2 Relationship between TLR4, MD-2, and CXCR7 protein expression and clinicopathological parameters in gastric cancer

\begin{tabular}{|c|c|c|c|c|c|c|c|}
\hline \multicolumn{8}{|l|}{ Gender } \\
\hline Male & 90 & 63 & 0.520 & 32 & 0.894 & 52 & 0.635 \\
\hline Female & 60 & 39 & & 49 & & 37 & \\
\hline \multicolumn{8}{|l|}{ Age (yrs) } \\
\hline$<60$ & 79 & 51 & 0.340 & 36 & 0.443 & 45 & 0.533 \\
\hline$\geq 60$ & 71 & 51 & & 45 & & 44 & \\
\hline \multicolumn{8}{|l|}{ Diameter $(\mathrm{cm})$} \\
\hline$<5.0$ & 93 & 67 & 0.175 & 53 & 0.348 & 61 & 0.046 \\
\hline$\geq 5.0$ & 57 & 35 & & 28 & & 28 & \\
\hline \multicolumn{8}{|l|}{ Lauren type } \\
\hline Intestinal type & 71 & 50 & 0.192 & 35 & 0.273 & 44 & 0.533 \\
\hline Diffuse type & 79 & 52 & & 46 & & 45 & \\
\hline \multicolumn{8}{|l|}{ Differentiation } \\
\hline Well-moderately & 92 & 59 & 0.201 & 51 & 0.657 & 53 & 0.588 \\
\hline Poorly & 58 & 43 & & 30 & & 36 & \\
\hline \multicolumn{8}{|c|}{ Lymph node metastasis } \\
\hline+ & 60 & 47 & 0.027 & 42 & 0.001 & 42 & 0.030 \\
\hline- & 90 & 55 & & 39 & & 47 & \\
\hline \multicolumn{8}{|l|}{ TNM stage } \\
\hline$|+| \mid$ & 83 & 47 & 0.001 & 38 & 0.025 & 37 & $<0.001$ \\
\hline$I I I+I V$ & 67 & 55 & & 43 & & 52 & \\
\hline
\end{tabular}


Table 3 The correlation between the expression of CXCR7 and TLR4 and MD-2 in gastric carcinoma

\begin{tabular}{|c|c|c|c|c|c|}
\hline \multirow[t]{2}{*}{ CXCR7 } & \multirow[t]{2}{*}{$n$} & \multicolumn{2}{|l|}{ TLR4 } & \multicolumn{2}{|l|}{ MD-2 } \\
\hline & & $\overline{(+)}$ & (\%) & $\overline{(+)}$ & (\%) \\
\hline Positive & 89 & 82 & $(92.1)$ & 60 & $(67.4)$ \\
\hline Negative & 61 & 20 & (32.8) & 21 & (33.3) \\
\hline$x^{2}$ & & 58.6 & & 15.9 & \\
\hline$P$ value & & $<0.001$ & & $<0.001$ & \\
\hline
\end{tabular}

group (Fig. 5a, b). Additionally, the expression of CXCR7 in the TLR4 and MD-2 knockdown groups was reduced compared with that in the scrambled shRNA group (Fig. 5c, Table 4). These results indicate that LPS-induced CXCR7 expression may enhance gastric cancer tumor growth in vivo through the TLR4/MD-2 pathway.

\section{Discussion}

Gastric cancer is one of the most common malignant tumors worldwide. HP infection is involved in gastric carcinogenesis and gastric cancer development. LPS is a lipid and polysaccharide complex that is a unique cell wall component in Gram-negative bacteria [19]. HP LPS is also the primary endotoxin and has a structure and characteristics similar to those of Escherichia coli LPS (E. coli-LPS). Additionally, LPS is the main virulence factor of $H P$ and is released from damaged cells or bacteria in tumor tissues [20]. Numerous studies have addressed the key mechanism by which inflammation-induced LPS signaling alters the invasive and metastatic potential of gastric cancer cells. In the present study, we confirmed that LPS can induce and promote SGC7901 cell proliferation and metastasis.

TLR4 activation can promote tumor progression by promoting apoptosis resistance, invasion, metastasis, and immune surveillance evasion. TLR4 is upregulated in many solid tumors, including gastric cancer [14, 21, 22]. LPS binds to TLR4 in tumor tissues and induces the synthesis of a variety of inflammatory mediators, including TNFa, IL8 and multiple chemokines. Subsequently, an inflammatory microenvironment is generated via MyD88-dependent and independent pathways, promoting tumor development [23-25]. Relevant clinical and experimental studies have shown that CXC chemokines, such as the CXCL12 (SDF-1)/CXCR4 axis, can promote tumor growth, invasion and angiogenesis [26-29]. CXCR7 was originally termed RDC-1 (an orphan receptor). Recently, CXCR7 has been shown to cause chemotaxis in $\mathrm{T}$ lymphocytes in response to CXCL12 (the CXCR4 ligand) and was thus identified as a second CXCL12 receptor. Growing evidence suggests that CXCR7 can activate downstream signal transduction molecules, impact cell adhesion and invasion and further promote tumor cell proliferation through a complex signaling cascade [30-33]. Reports on the relationship between CXCR7 and gastric cancer are relatively rare, and the exact mechanism underlying how CXCR7 promotes

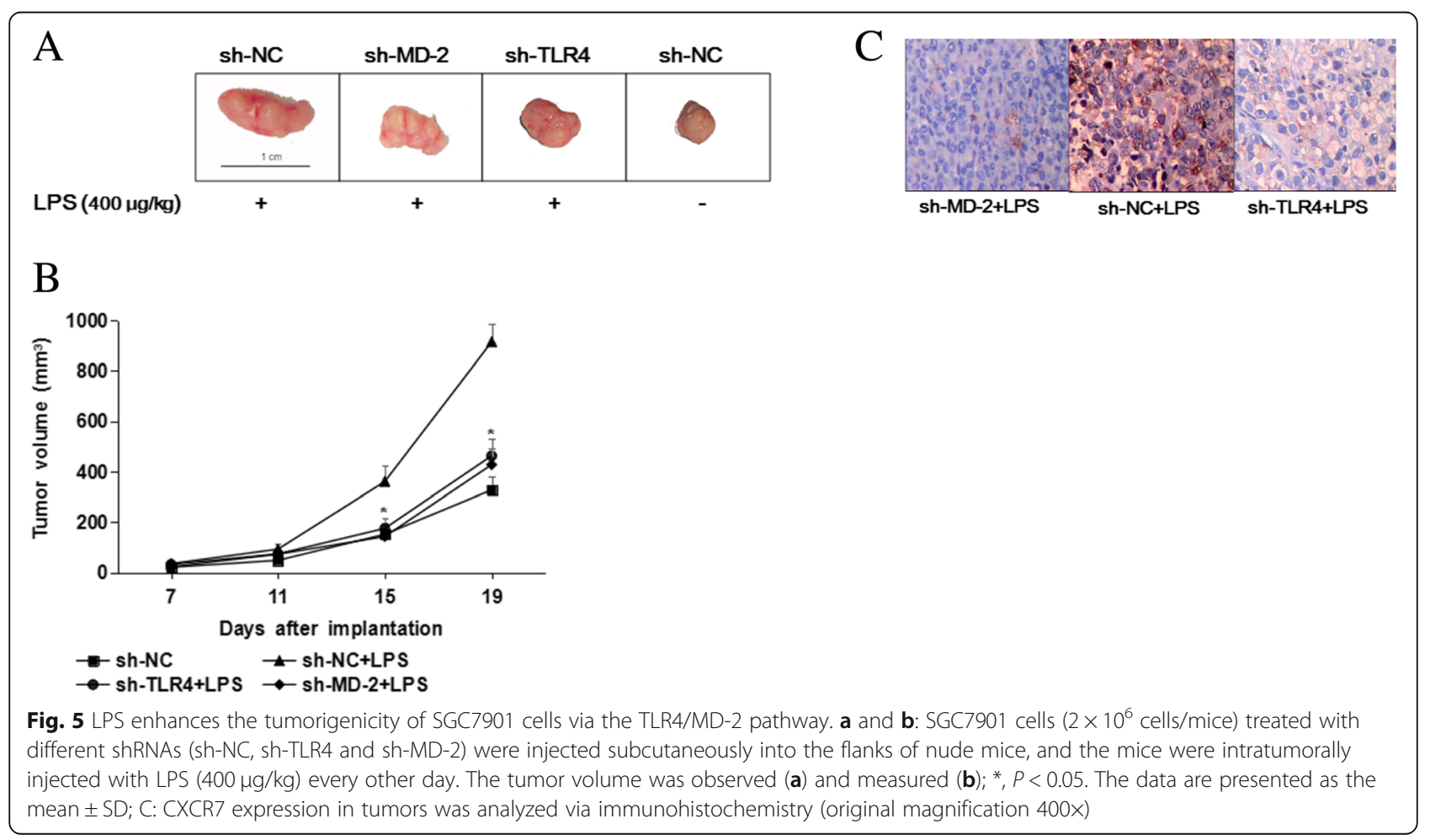


Table 4 The expression of CXCR7 protein in xenograft cells

\begin{tabular}{llll}
\hline group & $n$ & \multicolumn{2}{l}{ expression of CXCR7 } \\
\cline { 3 - 4 } & & $(-)$ & 1 \\
\hline sh-TLR4 + LPS & 6 & $5^{*}$ & 1 \\
sh-MD-2 + LPS & 6 & $5^{*}$ & 5 \\
sh-NC + LPS & 6 & 1 & 4 \\
sh-NC & 6 & 2 &
\end{tabular}

vs. sh-NC + LPS and sh-NC group, $P<0.05$

the occurrence and development of gastric cancer requires further study. In this study, our data elucidated the key mechanisms underlying the promotive effect of inflammation-derived LPS signaling on the metastatic potential of SGC7901 cells. LPS can upregulate CXCR7 expression through TLR4 signaling, thereby promoting gastric cancer cell proliferation and migration. Moreover, higher TLR4 and CXCR7 expression levels were found in gastric cancer tissues than in paracancerous normal tissues. TLR4 knockdown in SGC7901 cells revealed that this receptor is essential for LPS-induced CXCR7 expression. Additionally, we established a nude mouse xenograft model to further assess the function of the LPS/TLR4/CXCR7 pathway in gastric cancer. The results indicated that TLR4 and CXCR7 expression is related to gastric cancer growth and metastatic potential.

MD-2 is a recently discovered secreted glycoprotein. As an important regulator of innate immune recognition processes, MD-2 is a receptor molecule necessary for LPS to activate the TLR4 transmembrane signaling pathway $[34,35]$. Among all of the TLR4 accessory molecules, MD-2 is essential for the response to LPS [36, 37]. MD-2 mediates the release of proinflammatory cytokines through the formation of TLR4/MD-2 complexes following the recognition of bacterial LPSs. However, the regulatory mechanism and relationship between TLR4-MD-2 and CXCR7 in promoting gastric cancer development remains unknown. In the present study, we aimed to elucidate the connection between TLR4-MD-2 and CXCR7. The results indicated that CXCR7 expression was significantly increased in TLR4/MD-2-positive LPS-stimulated SGC7901 cells. Notably, LPS-mediated CXCR7 expression was blocked by TLR4 or MD-2 knockdown. Moreover, LPS did not affect CXCR7 expression in SGC7901 cells that expressed TLR4 but not MD-2. This result supports the notion that MD-2 is essential to the TLR4 signaling pathway. In addition, the expression level of MD-2 was significantly higher in gastric cancer tissues than in paracancerous control tissues. MD-2 expression was highly correlated with lymph node metastasis and TNM stage. Furthermore, our analysis of gastric cancer tissues from 150 patients showed that CXCR7 expression is positively correlated with that of TLR4 and MD-2 and that these three factors predict a worse prognosis and poorer survival. Nevertheless, more evidence should be obtained to confirm the mechanism underlying TLR4/MD-2 signaling through CXCR7 and the synergistic action of these molecules in tumor development and progression.

\section{Conclusions}

In summary, the LPS/TLR4 pathway is linked to gastric cancer development, and the interaction between TLR4, MD-2 and CXCR7 is closely related to tumor growth and metastasis. Understanding the relationship between microbiological signals and gastric cancer could have a major impact on tumor prevention and treatment.

\section{Abbreviations}

CXCR7: CXC chemokine receptor 7; HP : Helicobacter pylori;

IHC: Immunohistochemistry; LPS: Lipopolysaccharide; MD-2: Myeloid differential protein-2; PAMPs: Pathogen-related molecular patterns; RTPCR: Real-time polymerase chain reaction; TLR4: Toll-like receptor 4

\section{Acknowledgments}

We are grateful to Zenong Cheng at the Department of Pathology (Bengbu Medical College) for his assistance with the immunocytochemistry.

\section{Author contributions}

$L N, C Z G$ and XHB designed the study, analyzed the data and drafted the manuscript. OYR, ZQ and ZQ carried out sample collection and coordination. All of the authors read and approved the manuscript.

\section{Funding}

This work was supported by the Nature Science Key Program of College and University of Anhui Province (no. KJ2017A236), the Nature Science Foundation of Anhui Province (no. 1608085QH207), the Key projects of support program for outstanding young talents in Colleges and Universities of Anhui Province (no. gxyqZD2016161) and the Nature Science Key Program of Bengbu Medical College (no. BYKF1711, BYKY1650).

\section{Availability of data and materials}

The datasets obtained during and/or analyzed in the current study are available from the corresponding author on reasonable request.

\section{Ethics approval and consent to participate}

This study was approved by the Medical Ethics Committee of The First Affiliated Hospital of Bengbu Medical College and conducted in accordance with the ethical guidelines of the Declaration of Helsinki (no. BBMCEC2016024). None of the patients from whom the samples were obtained agreed to anticancer treatment before surgery. All of the individuals participating in this study provided written informed consent.

\section{Consent for publication}

Not applicable.

Competing interests

The authors declare that they have no competing interests.

\section{Publisher's Note}

Springer Nature remains neutral with regard to jurisdictional claims in published maps and institutional affiliations.

\section{Author details}

'Department of Pathology, The First Affiliated Hospital of Bengbu Medical College, Bengbu, China. ${ }^{2}$ Department of Pathology, Bengbu Medical College, Bengbu, China. ${ }^{3}$ Department of Endocrinology and Metabolism, Shanghai Jiaotong University Affiliated First People's Hospital, Shanghai, China. 
Received: 30 July 2018 Accepted: 4 January 2019

Published online: 12 January 2019

\section{References}

1. Global Burden of Disease Cancer Collaboration, Fitzmaurice C, Callen C, Barber RM, et al. Global, regional, and national cancer incidence, mortality, years of life lost, years lived with disability, and disability-adjusted life-years for 32 cancer groups, 1990 to 2015: a systematic analysis for the global burden of disease study. JAMA Oncol. 2017;3:524-48.

2. Lussana F, Rambaldi A. Inflammation and myeloproliferative neoplasms. J Autoimmun. 2017;85:58-63.

3. Tsai HF, Hsu PN. Modulation of tumor necrosis factor-related apoptosisinducing ligand (TRAIL)-mediated apoptosis by helicobacter pylori in immune pathogenesis of gastric mucosal damage. J Microbiol Immunol Infect. 2017;50:4-9.

4. Fox JG, Wang TC. Inflammation, atrophy, and gastric cancer. J Clin Invest. 2007:117:60-9.

5. Bae SE, Choi KD, Choe J, Kim SO, Na HK, Choi JY, Ahn JY, Jung KW, Lee J, Kim DH, Chang HS, Song HJ, Lee GH, Jung HY. The effect of eradication of Helicobacter pylori on gastric cancer prevention in healthy asymptomatic populations. Helicobacter. 2018;23:e12464.

6. Wang F, Meng W, Wang B, Qiao L. Helicobacter pylori-induced gastric inflammation and gastric cancer. Cancer Lett. 2014;345:196-202.

7. Lamb A, Chen LF. Role of the helicobacter pylori-induced inflammatory response in the development of gastric cancer. J Cell Biochem. 2013;114: 491-7.

8. Li G, Wang Z, Wang Z, Xu J, Cui J, Cai S, Zhan W, He Y. Gastric cancer patients with helicobacter pylori infection have a poor prognosis. J Surg Oncol. 2013;108:421-6.

9. Yokota S, Okabayashi T, Rehli M, Fujii N, Amano K. Helicobacter pylori lipopolysaccharides upregulate toll-like receptor 4 expression and proliferation of gastric epithelial cells via the MEK1/2-ERK1/2 mitogenactivated protein kinase pathway. Infect Immun. 2010;78:468-76.

10. Wang TR, Peng JC, Qiao YQ, Zhu MM, Zhao D, Shen J, Ran ZH. Helicobacter pylori regulates TLR4 and TLR9 during gastric carcinogenesis. Int J Clin Exp Pathol. 2014;7:6950-5.

11. Hishida A, Matsuo K, Goto Y, Mitsuda Y, Hiraki A, Naito M, Wakai K, Tajima K, Hamajima N. Toll-like receptor $4+3725 \mathrm{G} / \mathrm{C}$ polymorphism, helicobacter pylori seropositivity, and the risk of gastric atrophy and gastric cancer in Japanese. Helicobacter. 2009;14:47-53.

12. Hsieh $Y Y$, Shen $\mathrm{CH}$, Huang WS, Chin CC, Kuo YH, Hsieh MC, Yu HR, Chang TS, Lin TH, Chiu YW, Chen CN, Kuo HC, Tung SY. Resistin-induced stromal cell-derived factor-1 expression through toll-like receptor 4 and activation of p38 MAPK NFKB signaling pathway in gastric cancer cells. J Biomed Sci. 2014;21:59.

13. Liu S, Wang X, Shi Y, Han L, Zhao Z, Zhao C, Luo B. Toll-like receptor gene polymorphisms and susceptibility to Epstein-Barr virus-associated and -negative gastric carcinoma in northern China. Saudi J Gastroenterol. 2015; 21:95-103.

14. Li G, Wang Z, Ye J, Zhang X, Wu H, Peng J, Song W, Chen C, Cai S, He Y, Xu J. Uncontrolled inflammation induced by AEG-1 promotes gastric cancer and poor prognosis. Cancer Res. 2014;74:5541-52.

15. Ren W, Wang Z, Hua F, Zhu L. Plasminogen activator inhibitor-1 regulates LPS-induced TLR4/MD-2 pathway activation and inflammation in alveolar macrophages. Inflammation. 2015;38:384-93.

16. Zhang D, Li Y, Liu Y, Xiang X, Dong Z. Paclitaxel ameliorates lipopolysaccharide-induced kidney injury by binding myeloid differentiation protein-2 to block toll-like receptor 4-mediated nuclear factor-kappaB activation and cytokine production. J Pharmacol Exp Ther. 2013;345:69-75.

17. Hu H, Li Z, Zhu X, Lin R, Lin J, Peng J, Tao J, Chen L. Gua Lou Gui Zhi decoction suppresses LPS-induced activation of the TLR4/NF-kappaB pathway in BV-2 murine microglial cells. Int J Mol Med. 2013;31:1327-32.

18. Wang L, Zhao Y, Qian J, Sun L, Lu Y, Li H, Li Y, Yang J, Cai Z, Yi Q. Toll-like receptor-4 signaling in mantle cell lymphoma: effects on tumor growth and immune evasion. Cancer. 2013;119:782-91.

19. Esmaeilli D, Mobarez AM, Salmanian AH, Hosseini AZ. Bioactivity and immunological evaluation of LPS from different serotypes of Helicobacter pylori. Iran J Microbiol. 2013;5(2):142-6.

20. Washizaki A, Yonesaki T, Otsuka Y. Characterization of the interactions between Escherichia coli receptors, LPS and OmpC, and bacteriophage T4 long tail fibers. Microbiology. 2016 5(6):1003-15.
21. Oblak A, Jerala R. Toll-like receptor 4 activation in cancer progression and therapy. Clin Dev Immunol. 2011;2011:609579.

22. Guo J, Chen L, Luo N, Li C, Chen R, Qu X, Liu M, Kang L, Cheng Z. LPS/TLR4mediated stromal cells acquire an invasive phenotype and are implicated in the pathogenesis of adenomyosis. Sci Rep. 2016;6:21416.

23. Seol MA, Park JH, Jeong JH, Lyu J, Han SY, Oh SM. Role of TOPK in lipopolysaccharide-induced breast cancer cell migration and invasion. Oncotarget. 2017:8:40190-203.

24. Chen Y, Wu Z, Yuan B, Dong Y, Zhang L, Zeng Z. MicroRNA-146a-5p attenuates irradiation-induced and LPS-induced hepatic stellate cell activation and hepatocyte apoptosis through inhibition of TLR4 pathway. Cell Death Dis. 2018;9:22.

25. Zhao Y, Kong X, Li X, Yan S, Yuan C, Hu W, Yang Q. Metadherin mediates lipopolysaccharide-induced migration and invasion of breast cancer cells. PLoS One. 2011;6:e29363.

26. Zhao C, Lu X, Bu X, Zhang N, Wang W. Involvement of tumor necrosis factor-alpha in the upregulation of CXCR4 expression in gastric cancer induced by helicobacter pylori. BMC Cancer. 2010;10:419.

27. Xue LJ, Mao XB, Ren LL, Chu XY. Inhibition of CXCL12/CXCR4 axis as a potential targeted therapy of advanced gastric carcinoma. Cancer Med. 2017;6:1424-36.

28. Feng YF, Guo H, Yuan F, Shen MQ. Lipopolysaccharide promotes choroidal neovascularization by up-regulation of CXCR4 andCXCR7 expression in choroid endothelial cell. PLoS One. 2015;10:e0136175.

29. Sun X, Cheng G, Hao M, Zheng J, Zhou X, Zhang J, Taichman RS, Pienta KJ, Wang J. CXCL12/CXCR4/CXCR7 chemokine axis and cancer progression. Cancer Metastasis Rev. 2010;29:709-22.

30. Sánchez-Martín L, Sánchez-Mateos P, Cabañas C. CXCR7 impact on CXCL12 biology and disease. Trends Mol Med. 2013;19:12-22.

31. Shi HT, Shi AM, Wang Y, Dong L, Zhao G, Li Y, Lu XL. Expression of CXCR7 in gastric Cancer cells and its effect on the migration and invasion of SGC7901 cells. Sichuan Da Xue Xue Bao Yi Xue Ban. 2016;47:685-90.

32. Shi A, Shi H, Dong L, Xu S, Jia M, Guo X, Wang T. CXCR7 as a chemokine receptor for SDF-1 promotes gastric cancer progression via MAPK pathways. Scand J Gastroenterol. 2017:52:745-53.

33. Nambara S, Iguchi T, Oki E, Tan P, Maehara Y, Mimori K. Overexpression of CXCR7 is a novel prognostic Indicator in gastric Cancer. Dig Surg. 2017;34: 312-8.

34. Kim KH, Jo MS, Suh DS, Yoon MS, Shin DH, Lee JH, Choi KU. Expression and significance of the TLR4/MyD88 signaling pathway in ovarian epithelial cancers. World J Surg Oncol. 2012;10:193.

35. Dey G, Bharti R, Ojha PK, Pal I, Rajesh Y, Banerjee I, Banik P, Parida S, Parekh A, Sen R, Mandal M. Therapeutic implication of 'Iturin A' for targeting MD-2/ TLR4 complex to overcome angiogenesis and invasion. Cell Signal. 2017;35: 24-36.

36. Luo M, Hu L, Li D, Wang Y, He Y, Zhu L, Ren W. MD-2 regulates LPS-induced NLRP3 inflammasome activation and IL-1 beta secretion by a MyD88/NF-KBdependent pathway in alveolar macrophages cell line. Mol Immunol. 2017; 90:1-10.

37. Ishihara S, Rumi MA, Kadowaki Y, Ortega-Cava CF, Yuki T, Yoshino N, MiyaokaY KH, Ishimura N, Amano Y, Kinoshita Y. Essential role of MD-2 in LPS responsiveness and TLR4 distribution. J Immunol. 2004;173(2):1406-16.

Ready to submit your research? Choose BMC and benefit from:

- fast, convenient online submission

- thorough peer review by experienced researchers in your field

- rapid publication on acceptance

- support for research data, including large and complex data types

- gold Open Access which fosters wider collaboration and increased citations

- maximum visibility for your research: over $100 \mathrm{M}$ website views per year

At BMC, research is always in progress.

Learn more biomedcentral.com/submissions 